\title{
Healthcare Resource Utilization and Costs Associated with Ketosis Events in Pediatric and Adult Patients with Type 1 Diabetes Mellitus in the UK
}

\author{
Nandu Thalange - Natalie Valerie Jane Aldhouse (D) Helen Kitchen • \\ Daniel Howard · Deniz Tutkunkardas · Jonas Håkan-Bloch
}

Received: August 11, 2017 / Published online: September 13, 2017

(C) The Author(s) 2017. This article is an open access publication

\begin{abstract}
Introduction: Ketosis is a metabolic state associated with insulin deficiency. Untreated, it develops into diabetic ketoacidosis, a significant contributor to mortality and morbidity in people with type 1 diabetes mellitus (T1DM). Little is understood about how patients utilize healthcare resources during ketosis events. This study aimed to identify and quantify healthcare resource utilization and provide estimates of associated costs of ketosis events in T1DM, treated unaided or with healthcare professional (HCP) assistance in the UK.

Methods: Qualitative interviews with adult patients, pediatric carers, and HCPs identified
\end{abstract}

Enhanced content To view enhanced content go to http://www.medengine.com/Redeem/ 890CF060216F91B6.

Electronic supplementary material The online version of this article (doi:10.1007/s13300-017-0305-0) contains supplementary material, which is available to authorized users.

N. Thalange

Norfolk and Norwich University Hospital, Norwich, UK

N. V. J. Aldhouse $(\bowtie) \cdot$ H. Kitchen · D. Howard

DRG Abacus, Manchester, UK

e-mail: naldhouse@teamdrg.com

D. Tutkunkardas $\cdot$ J. Håkan-Bloch

Novo Nordisk A/S, Søborg, Denmark resources used by patients/carers during ketosis events. An online quantitative survey was then used to quantify patients/carers resource use during their/their child's most recent ketosis event, and HCPs estimated patient resource uptake to corroborate the findings. Associated costs estimated from UK data sources were applied to the survey results to calculate the cost of ketosis events in adults and children.

Results: Quantitative survey responses from 93 adults, 76 carers, and 52 HCPs were analyzed. Patients and carers monitored ketosis during and following the event with ketone strips and additional glucose strips, and administered treatment comprising insulin and pump set changes where appropriate. Additionally, patients/carers accessed phone services and many received follow-up medical appointments. In total, $70 \%(n=65)$ of adult and $66 \%$ $(n=50)$ of pediatric ketosis events were managed at home, for which resource use costs per event were $£ 23.87$ and $£ 38.00$ respectively. Remaining events were treated in NHS facilities costing £217.57 per adult and £352.92 per child. Weighted averages identified that ketosis events cost $£ 81.98$ per adult and $£ 142.97$ per child. Indirect costs from work productivity loss increase these figures to $£ 225.11$ per adult and $£ 256.88$ per child.

Conclusions: Healthcare resource use for ketosis events is high in adults and children with T1DM and imposes an underappreciated economic burden for the NHS. 
Funding: Novo Nordisk A/S.

Keywords: Healthcare cost; Hospitalization; Ketosis resource utilization; Type 1 diabetes

\section{INTRODUCTION}

Hypoglycemia and hyperglycemia with ketosis are the two most common acute complications in established type 1 diabetes mellitus (T1DM). However, while self-management of hypoglycemia is well documented in the literature [1], there is little information available regarding the management of ketosis events.

Defined as the presence of elevated ketone bodies in the blood, and arising during periods of insulin deficiency and increased concentrations of counter-regulatory hormones [2], ketosis is often asymptomatic, but at high levels patients may experience nausea or abdominal pain [2]. Common causes of ketosis include infection, gastrointestinal illness, insulin omission, and exercise, and its incidence may be increased in insulin pump users [2].

It is generally recommended that compensatory actions should be taken when blood ketone levels are greater than $0.6 \mathrm{mmol} / \mathrm{L}$ [3]. Unidentified and untreated, high ketone levels cause the body to enter diabetic ketoacidosis (DKA), which is defined as a state of metabolic acidosis, ketosis, and hyperglycemia [2]. Diabetic ketoacidosis is a common and significant contributor to morbidity and mortality in people with T1DM [4] and is associated with high hospitalization and healthcare resource costs. In 2015, over 7000 patients were hospitalized for DKA in the UK, at a cost to the National Health Service (NHS) of almost $£ 10,000,000$ [5-7].

Patients should be taught to identify and initiate treatment of ketosis to prevent progression to DKA [8]. The National Institute for Health and Care Excellence (NICE) advises ketone monitoring with blood ketone strips for children, and urine or blood ketone strips for adults in the sick-day rules for T1DM $[9,10]$. Where raised ketones are identified, patients are instructed to adjust their insulin dose and increase their liquid intake. While NICE does not provide guidelines on insulin dose adjustments, the British Society for Paediatric Endocrinology and Diabetes advises the administration of $10 \%$ of a patient's daily dose where ketone levels are $0.6-1.5 \mathrm{mmol} / \mathrm{L}$, or $20 \%$ where levels are greater than $1.5 \mathrm{mmol} / \mathrm{L} \mathrm{[3].} \mathrm{At}$ ketone levels above $3.0 \mathrm{mmol} / \mathrm{L}$, patients should seek medical assistance [11, 12]. However, a preliminary literature review identified no publications reporting actual healthcare resource use during and following ketosis events, or the associated costs.

This study aimed to quantify the cost of healthcare resource utilization in the UK attributable to ketosis events in adults and children with T1DM.

\section{METHODS}

\section{Qualitative Interviews}

Qualitative interviews were conducted with healthcare professionals (HCPs), adult carers of children with T1DM, and adults with T1DM to identify the resources used during ketosis events and to understand how these resources were accessed by patients. Telephone interviews lasted for $60 \mathrm{~min}$ and were conducted by an experienced qualitative researcher, using semi-structured interview guides developed in collaboration with an independent diabetes expert (available in the supplementary material). HCPs comprised consultant endocrinologists, consultant pediatricians, and diabetes specialist nurses (DSNs) all working within the NHS; all participants were UK residents. All participants were provided with honoraria.

The need for a full ethics review was discussed with the North West Research Ethics Committee (ethics committee reference number 60/32/07) and was deemed unnecessary. As this was a non-interventional interview/survey study, the trial was not registered. All procedures followed were in accordance with the ethical standards of the responsible committee on human experimentation (institutional and national) and with the Helsinki Declaration of 1964, as revised in 2013. The study was also conducted in line with National Institute of 
Health Research Good Clinical Practice [13] and British Healthcare Business Intelligence Association ethical standards [14]. Informed consent was obtained from all patients for being included in the study; all data was anonymized and held confidentially.

Topics of discussion included the patient/carer's understanding of ketosis, the advice and education available to patients, and the NHS services that would be utilized by patients requiring HCP assistance. Patients and carers additionally discussed their most recent experience of ketosis, recounting the resources they had used for ketone monitoring and treatment, and any HCP assistance received.

Interviews were audio-recorded, transcribed verbatim, and analyzed using thematic methods facilitated by ATLAS.ti qualitative data analysis software (ATLAS.ti GmbH, Berlin, version 7). Each transcript was read and coded according to common themes of resource use. The findings from these qualitative interviews were then used to inform the content and wording of a quantitative survey.

\section{Quantitative Online Survey}

Quantitative online surveys (available in the supplementary material) were conducted with HCPs, adults with T1DM, and adult carers of children with T1DM to quantify the average use of each of the resources identified during the qualitative interviews. HCPs comprising consultant endocrinologists, consultant pediatricians, and DSNs were identified from a database of specialists, with eligibility confirmed by General Medical Council number for doctors and Nursing and Midwifery Council registration number for nurses. Patients and carers were recruited from throughout the UK via a pre-existing panel and confirmed their/their child's diagnosis of T1DM by supplying a scanned image or photograph of their medication and/ or prescription. All participants were provided with honoraria.

To ensure that participants had relevant experience to respond to survey questions, inclusion/exclusion criteria were developed. HCPs were required to work within the NHS and to have treated/managed patients with T1DM during ketosis events within the past 1 month. Patients/carers were all at least 18 years of age; all patients were diagnosed for a minimum of 12 months, had collected a prescription for ketone strips in the past 12 months, and to reduce recall bias had experienced a ketosis event within the past 12 months. Patients/carers were provided with clear definitions of ketosis and DKA and were reminded throughout the survey that they were being asked only about resource use during periods of ketosis.

Separate surveys were administered to HCPs and patients/carers. Participants received an email with a unique link to the survey to ensure that it could not be accessed by those not invited. Each survey began with a screen providing the respondent with study information, and all respondents provided informed consent before any personal or survey data were collected.

Submitted data were checked for quality, and responses that were likely erroneous or unreliable were systematically removed using standard statistical approaches; outlying data were defined as any numerical value more than 1.5 interquartile range below the first or above the third quartile of responses [15]. All participants identified as submitting either the same response to at least $50 \%$ of all questions or where at least $20 \%$ of their responses were calculated as outliers were removed from the analyzed dataset.

Statistical testing of responses was performed using chi-squared tests for categorical data and Wilcoxon rank-sum (WRS) tests for continuous data. WRS tests were used as the continuous data did not fit a parametric distribution. All analyses were performed in STATA version 14.2 (Statacorp LLC).

\section{Cost Calculations}

Resource costs were retrieved from the Department of Health, British National Formulary, Personal Social Services Research Unit, National Careers Service, and the Office for National Statistics (please see Table S1 in the supplementary material for details).

The incidence of ketosis in the UK was identified via a literature review, with one 
clinical trial paper reporting these data only and indicating an annual incidence of $6.9 \%$ [16]. T1DM prevalence data were obtained via Diabetes UK, who reported a prevalence of $0.60 \%$ in $2015[17,18]$.

\section{RESULTS}

\section{Qualitative Interviews}

HCP interviews were conducted with 10 consultant endocrinologists and five DSNs. Eight interviews focused on the treatment of pediatric patients, and seven on the treatment of adult patients. Interviews were conducted with 10 adult patients and 11 carers of pediatric patients. Participant characteristics are presented in the supplementary material (Tables S2 and S3).

Patient and carers discussed resources they had used during previous ketosis events and additional resources that they were aware of. HCPs reported the services that they offered and the assistance they gave to patients seeking their help. Primarily, patients and carers used either blood or urine ketone strips to monitor ketone levels, additional glucose strips to closely monitor glucose levels, and additional doses of insulin to counteract the raised ketone levels. As insulin pump faults are a common cause of ketosis events, patients and carers reported conducting cannula changes where applicable. Phone services were identified as valuable sources of advice. Patients had used, or were aware of, phone services provided by diabetes clinics, their local hospital, their general practitioner, NHS Direct, pump manufacturers, and charities such as Diabetes UK.

The interviews revealed resource use that continued beyond the ketosis event itself; patients continued to use resources and services for several days after ketone levels had returned to normal. Follow-up phone calls or in-person appointments with HCPs were common. Additionally, whilst HCPs reported that ketosis events should not necessitate significant time away from work or school, patients and carers reported that ketosis events were indeed associated with some days of absenteeism. A full list of all resources discussed is presented with associated patient quotes in Table 1 .

\section{Quantitative Survey}

The patient/carer survey listed each resource identified during the qualitative interviews and asked respondents to quantify their use of each resource during their/their child's most recent ketosis event. HCPs were asked to estimate the availability and uptake of each resource amongst their own patients. In total, 108 adult patients, 122 pediatric carers, and 56 HCPs completed the surveys. Following the data cleansing process outlined in the "Methods" section, the final dataset comprised 93 adult patients (Table 2 ), 76 pediatric carers (Table 2 ), and 52 HCPs (Table 3).

Over $50 \%$ of adult patients and pediatric carers had experienced their/their child's most recent ketosis event within the past 3 months, allowing relatively recent recall of events. While most adult patients were aged between 26 and 74 , young adult patients aged 18-25 and elderly patients aged 75 years or more were also represented. Pediatric patient ages were similarly well represented, with $11 \%$ of carers discussing ketosis events in children 4 years of age or less. Patients and carers had a broad range of knowledge and education on the management of ketosis events. When asked "How well do you understand how to identify and manage ketones?" only $2 \%$ of respondents responded "Not at all," with 35\% responding "Somewhat," 35\% "Mostly," and 27\% "Completely." Amongst those eligible for a place on a Dose Adjustment For Normal Eating (DAFNE) course, $42 \%$ had attended.

\section{Resource Use}

Of the adults surveyed, 70\% treated their most recent ketosis event entirely within their home or workplace, while 30\% made use of some healthcare resources at home before seeking in-person assistance in NHS facilities. Amongst pediatric carers, these figures were $66 \%$ and $33 \%$, respectively. Resource utilization is presented in Fig. 1 for adult patients and in Fig. 2 for pediatric patients and their carers. 
Table 1 Quantitative interview findings: resources used by patients and carers during ketosis events

\begin{tabular}{|c|c|}
\hline Resource & Patient/carer quote describing resource use \\
\hline Ketone strips & $\begin{array}{l}\text { "I always try to have at least a couple of boxes of ketone strips in because you only } \\
\text { get them in boxes of } 10 \text {, and so if she's ill then you might use a whole box in a } \\
12 \text {-h period to check her ketones." - Carer of a 6-year-old child with T1DM }\end{array}$ \\
\hline Additional glucose strips & $\begin{array}{l}\text { "Normally I check [my glucose] about four times a day, but on that day because } \\
\text { [my ketones] had been high it was about seven or eight." - Adult with T1DM }\end{array}$ \\
\hline Insulin & $\begin{array}{l}\text { "However much she has in the day at that time of her normal insulin we give a } \\
\text { certain number of extra units. I seem to remember it was seven extra units I gave } \\
\text { her at that point... we did it twice... Usually it gets rid of it after two } \\
\text { [doses]." - Carer of an } 11 \text {-year-old child with T1DM }\end{array}$ \\
\hline Pump set changes & $\begin{array}{l}\text { "I think on this occasion we changed the set, her cannula, and gave her a correction } \\
\text { with her pump... If it's a set issue, we always change the set." - Carer of a } \\
\text { 6-year-old child with T1DM }\end{array}$ \\
\hline Phone services & $\begin{array}{l}\text { "I just think I was out of my comfort zone, and I needed reassurance and somebody } \\
\text { to talk me through what to do because I wasn't at home with everything there, I } \\
\text { had limited resources with me. It was just a bit of a panic situation really." - } \\
\text { Adult with T1DM }\end{array}$ \\
\hline $\begin{array}{l}\text { Follow-up phone or in-person } \\
\text { appointments with HCPs }\end{array}$ & $\begin{array}{l}\text { "I had this nurse calling me the following day, she had a handover from the night } \\
\text { nurse, and asking me just to make sure everything was back to normal, and that } \\
\text { was it, that she was happy and just to make sure that I was okay with } \\
\text { everything." - Carer of a 6-year-old child with T1DM }\end{array}$ \\
\hline Time missed from work & $\begin{array}{l}\text { "I took the day off work and the next day I went into work literally half day."- } \\
\text { Carer of a 14-year-old child with T1DM } \\
\text { "I couldn't do any work that day because it wouldn't have been good work that I } \\
\text { would have produced." - Adult with T1DM }\end{array}$ \\
\hline
\end{tabular}

HCP healthcare professional, TIDM type 1 diabetes mellitus

Overall, pediatric carers were observed to use more ketone and glucose strips during the ketosis event when compared with adult patients, and more strips were used by patients/carers attending hospital or community services than those successfully treating events in the home. While $67 \%$ of pediatric carers preferred to use blood ketone strips to monitor their child's ketones, this figure was only $57 \%$ amongst adults, with the remainder opting for urine strips.

A greater number of carers made use of phone services or sought assistance in NHS facilities when compared with adult patients. Phone services were accessed by $22 \%$ of adults and $37 \%$ of carers. Overall, adult patients commonly made use of generic services such as GP phone lines or NHS 111, while carers tended to directly contact diabetes specialists (please see Fig. S1 in the supplementary material). No participants reported phoning a pump manufacturer helpline or charity services such as Diabetes UK. When asked why they had not made a phone call, only $67 \%$ of adults and $54 \%$ of carers responded that it was because they had not needed to. Patients and carers that may have benefited from phone services failed to call because they needed assistance outside of working hours $(29 \%$ adults, $36 \%$ carers $)$, because they did not think they had access to a 
Table 2 Demographic characteristics of participants included in quantitative survey analysis

\begin{tabular}{lll}
\hline Demographic & Adult & Pediatric \\
characteristic & patients, & patients/carers, \\
& $n(\%)$ & $n(\%)(N=76)$ \\
& $(N=93)$ & \\
\hline
\end{tabular}

Patient's gender

$\begin{array}{lll}\text { Male } & 27(29) & 32(42) \\ \text { Female } & 66(71) & 43(57) \\ \text { Prefer not to say } & 0 & 1(1) \\ \begin{array}{l}\text { Patient's age (years) } \\ 0-4\end{array} & \text { N/A } & 8(11) \\ 5-11 & \text { N/A } & 36(47) \\ 12-18 & \text { N/A } & 32(42) \\ 18-25 & 16(17) & \text { N/A } \\ 26-74 & 75(81) & \text { N/A } \\ \geq 75 & 2(2) & \text { N/A }\end{array}$

Patient's ethnicity

\begin{tabular}{lll} 
Asian & $5(5)$ & $5(7)$ \\
Black & $3(3)$ & $1(1)$ \\
White & $80(86)$ & $54(71)$ \\
Other ethnic group & $1(1)$ & 0 \\
Multiethnic & $4(4)$ & $16(21)$ \\
Employment (adult patients and \\
$\begin{array}{l}\text { pediatric carers) } \\
\begin{array}{l}\text { Full- or part-time paid } \\
\text { employment }\end{array}\end{array}$ \\
$\begin{array}{l}\text { Volunteer work/ } \\
\text { looking for work }\end{array}$ & $3(3)$ & $54(71)$ \\
$\begin{array}{l}\text { Full-time homemaker/ } \\
\text { retired }\end{array}$ & $14(15)$ & $10(13)$ \\
$\begin{array}{l}\text { Student } \\
\begin{array}{l}\text { Not working due to } \\
\text { own/child's T1DM }\end{array}\end{array}$ & $4(4)$ & $8(11)$ \\
$\begin{array}{l}\text { Not working due to } \\
\text { medical problems } \\
\text { other than T1DM }\end{array}$ & $4(4)$ & 0 \\
\hline
\end{tabular}

Table 2 continued

\begin{tabular}{lll}
\hline Demographic & Adult & Pediatric \\
characteristic & patients, & patients/carers, \\
& $n(\%)$ & $n(\%)(N=76)$ \\
& $(N=93)$ & \\
\hline
\end{tabular}

Education (adult patients and pediatric carers)

\begin{tabular}{|c|c|c|}
\hline University education & $44(47)$ & $37(49)$ \\
\hline $\begin{array}{l}\text { Diploma in higher } \\
\text { education }\end{array}$ & $17(18)$ & $10(13)$ \\
\hline A/AS level & $19(20)$ & $16(21)$ \\
\hline GCSE/O level & $11(12)$ & $12(16)$ \\
\hline None of the above & $2(2)$ & $1(1)$ \\
\hline \multicolumn{3}{|c|}{ Time since diagnosis (years) } \\
\hline $1-2$ & $8(9)$ & $21(28)$ \\
\hline $3-5$ & $18(19)$ & $32(42)$ \\
\hline $6-10$ & $11(12)$ & $17(22)$ \\
\hline$\geq 11$ & $56(60)$ & $6(8)$ \\
\hline
\end{tabular}

Insulin preparation $^{\mathrm{a}}$

$\begin{array}{lll}\text { Basal-bolus } & 41(44) & 21(28) \\ \text { Mixed insulin } & 23(25) & 30(39) \\ \text { Pump } & 35(38) & 30(39) \\ \text { Other } & 2(2) & 1(1) \\ \text { Unsure } & 4(4) & 2(3)\end{array}$

Time since patient's most recent ketosis event (months)

$\begin{array}{lll}0-3 & 54(58) & 36(47) \\ 4-6 & 28(30) & 27(36) \\ 7-9 & 6(6) & 11(14) \\ 10-12 & 5(5) & 2(3)\end{array}$

DAFNE course

attendance

$\begin{array}{lll}\text { Yes } & 39(42) & \text { N/A } \\ \text { No } & 54(48) & \text { N/A }\end{array}$

Perceived level of ketone knowledge and understanding (adult patients/pediatric carers)
Not at all
$1(1)$
$2(3)$
Somewhat
$32(34)$ 
Table 2 continued

\begin{tabular}{lll}
\hline $\begin{array}{l}\text { Demographic } \\
\text { characteristic }\end{array}$ & $\begin{array}{l}\text { Adult } \\
\text { patients, } \\
\boldsymbol{n}(\%) \\
(\boldsymbol{N}=\mathbf{9 3})\end{array}$ & $\begin{array}{l}\text { Pediatric } \\
\text { patients/carers, } \\
\boldsymbol{n}(\%)(\boldsymbol{N}=\mathbf{7 6})\end{array}$ \\
\hline $\begin{array}{l}\text { Mostly } \\
\text { Completely }\end{array}$ & $38(41)$ & $33(43)$ \\
\hline
\end{tabular}

Patient's highest ketone level during most recent ketosis event $(\mathrm{mmol} / \mathrm{L})$

\begin{tabular}{lll}
$0-1.5$ & $19(20)$ & $19(25)$ \\
$1.5-3.0$ & $52(56)$ & $40(53)$ \\
$>3.0$ & $22(24)$ & $17(22)$ \\
\hline
\end{tabular}

A level Advanced Level General Certificate of Education, $A S$ level Advanced Subsidiary Level General Certificate of Education, DAFNE Dose Adjustment For Normal Eating, GCSE General Certificate of Secondary Education, N/A not applicable, $O$ level General Certificate of Education: Ordinary Level; TIDM type 1 diabetes mellitus

${ }^{\text {a }}$ Participants could select more than one response

phone service ( $17 \%$ adults, $45 \%$ carers), or for another unspecified reason (4\% adults, 5\% carers). Another $29 \%$ of adult patients and $9 \%$ of pediatric carers approached an in-person NHS facility directly, rather than using a phone service.

Of the patients treated in NHS facilities, adults were most often treated in Accident and Emergency (43\%) while pediatric patients tended to be admitted to a hospital ward (54\%). Approximately $36 \%$ of adults and $27 \%$ of pediatrics were treated in the community, e.g., in diabetes clinics or by their GP. Overall, $26 \%$ of adult patients and $12 \%$ of pediatrics progressed to DKA following treatment for ketosis.

Most adult patients and carers continued to monitor ketone and glucose levels closely over the hours/days following the event, although carers were observed to use ketone and glucose strips at a greater frequency than the adult patients. Many participants received follow-up phone calls or appointments, but this was far more common for children than adults.
Table 3 Demographic characteristics of HCPs included in quantitative survey analysis

\begin{tabular}{ll}
\hline Demographic characteristic & $\begin{array}{l}\text { Participants, } n(\%) \\
(N=52)\end{array}$
\end{tabular}

Job title

Consultant $\quad 45(87)$

Diabetes specialist nurse $\quad 7(13)$

Primary patient type

Adults

Pediatrics

$16(31)$

Years qualified

$\begin{array}{lc}0-10 & 2(4) \\ 11-20 & 17(33) \\ 21-30 & 30(58) \\ \geq 31 & 3(6)\end{array}$

Years with a diabetes/endocrinology focus

$0-10$

$11-20$

$21-30$

$\geq 31$

No diabetes/endocrinology focus

Hospital/clinic location

Urban

Rural

Hospital/clinic type

Children's hospital

Community hospital

Teaching/university hospital

Diabetes clinic

$H C P$ healthcare professional

Indirect Resource Use

Indirect resources such as absenteeism and presenteeism were identified. Adults missed $7-21 \mathrm{~h}$ of work because of their ketosis event and carers of pediatric patients 5-18 h (Table 4). 


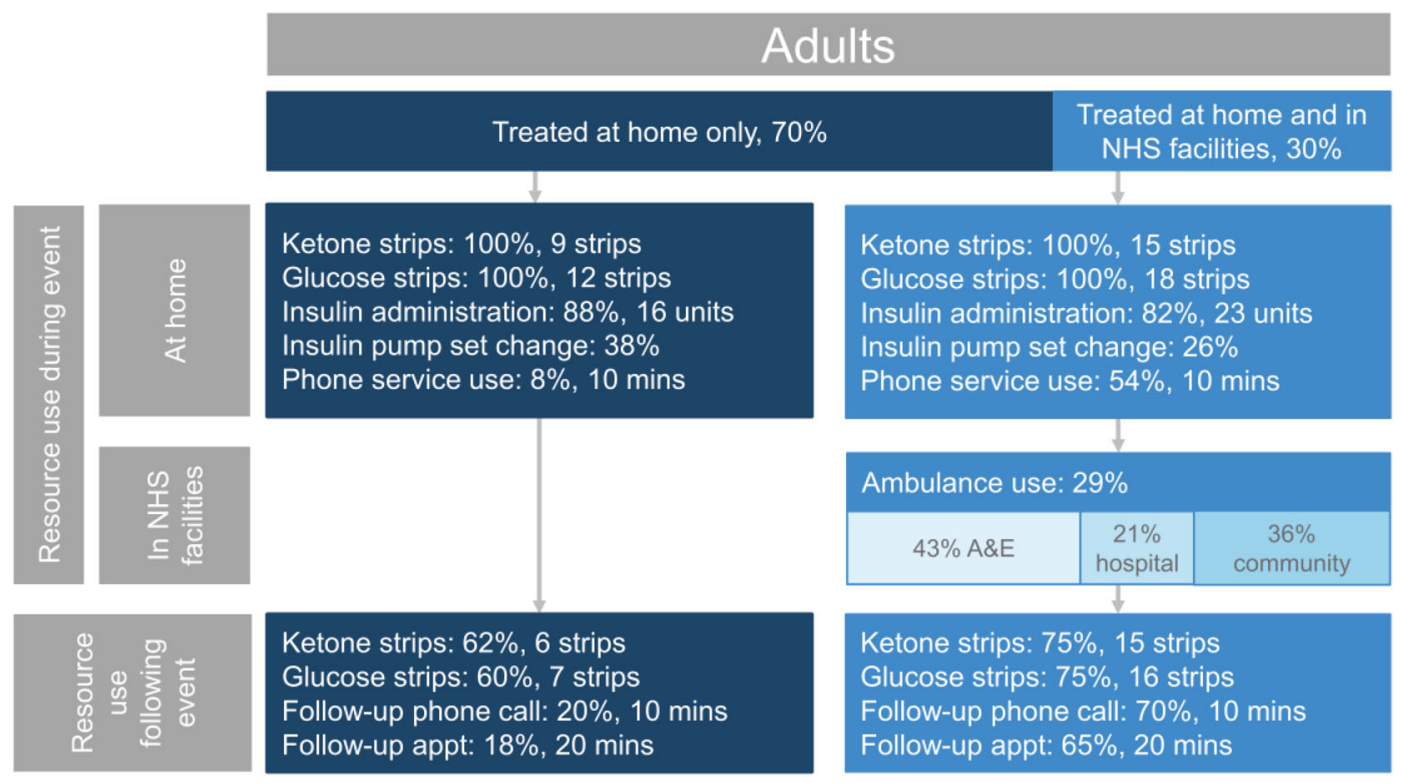

Fig. 1 Resource use by adults during ketosis events. Data presented are conditional means. A\&E accident \& emergency, appt appointment, NHS National Health Service, pts patients

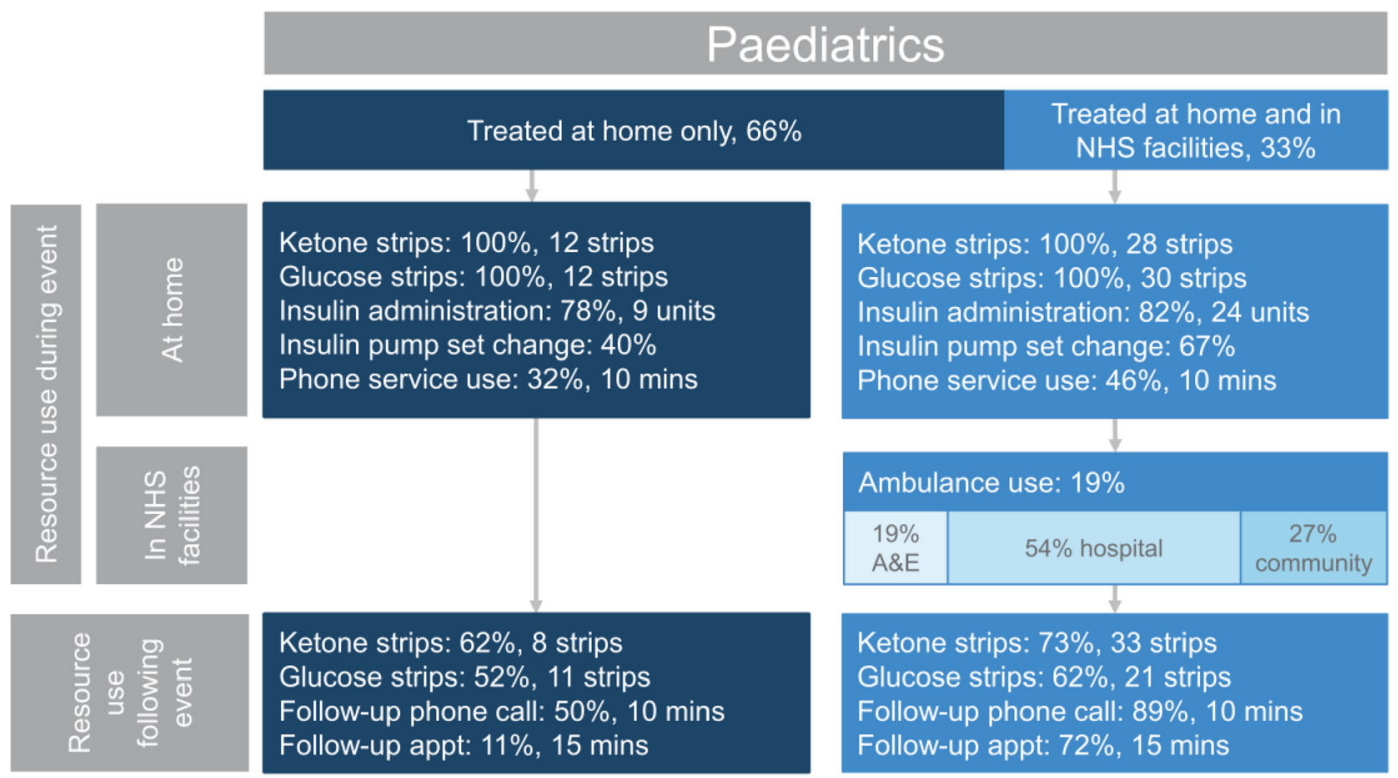

Fig. 2 Resource use by children and their carers during ketosis events. Data presented are conditional means. A\&E accident \& emergency, appt appointment, NHS National Health Service, pts patients

Participants were further asked to estimate the impact their most recent ketosis event had had on their work productivity in the 7 days following the event on a scale from 0 to 10 , where 0 represented "My/my child's raised ketones had no effect on my work" and 10 represented "My/my child's raised ketones completely prevented me from working." Median scores ranged from 4 for adult patients treated at home to 8 for both adults and the carers of pediatric patients treated in NHS services. An impact on daily activities for adult 
Table 4 Indirect costs associated with time away from work because of a ketosis event

\begin{tabular}{lcc}
\hline & $\begin{array}{l}\text { Hours of work } \\
\text { lost, mean } \\
(\text { SD })\end{array}$ & $\begin{array}{l}\text { Associated } \\
\text { cost }(\mathfrak{E})\end{array}$ \\
\hline $\begin{array}{l}\text { Adults treated entirely in } \\
\text { the home }\end{array}$ & $7(13)$ & 90.74 \\
$\begin{array}{l}\text { Adults treated in the } \\
\text { home and in NHS }\end{array}$ & $21(15)$ & 265.37 \\
facilities & \\
$\begin{array}{l}\text { Carers of children treated } \\
\text { entirely in the home }\end{array}$ & $5(6)$ & 56.57 \\
$\begin{array}{l}\text { Carers of children treated } \\
\text { in the home and in }\end{array}$ & 228.58 \\
NHS facilities & \\
\hline NHS National Health Service, $S D$ standard deviation
\end{tabular}

patients and carers and time away from school for pediatric patients were other common experiences.

\section{Costs}

\section{Direct Costs}

The direct costs of ketosis events were estimated as $£ 81.98$ for adult patients and $£ 142.97$ for children. These figures are weighted averages for events treated either at home or with the assistance of HCPs in NHS facilities and comprise the associated costs for ketone monitoring, glucose monitoring, insulin administration, insulin pump set change, phone service usage, in-person appointment costs, and NHS facility, staff, and treatment costs. Total costs per resource are presented in Table 5 and illustrated in Fig. 3.

The greater cost associated with pediatric events compared with events in adults may be attributed to the significantly greater proportion of patients admitted to hospital for treatment and significantly increased use of phone services amongst pediatric carers $\left(\chi^{2}\right.$, all $p<0.05)$. Pediatric carers were additionally observed to use significantly greater numbers of ketone strips during and following the event (WRS, $p<0.05$ ), but no other statistical differences in resource use were observed. Full statistical findings are presented in the supplementary material (Tables S4 and S5).

In the UK, the annual direct population cost of ketosis events was estimated as $£ 2,598,405$ (Table S6 in the supplementary material).

\section{Indirect Costs}

Indirect costs of ketosis events were calculated for adults and pediatric carers in full-time work from the mean UK salary ( $£ 501 /$ week). Ketosis events were estimated to cost between $£ 90.74$ and $£ 265.37$ in lost earnings (Table 4). The UK mean employment rate (75\%) was applied to the total costs to account for unemployment.

\section{Sensitivity Analysis}

A one-way deterministic sensitivity analysis was conducted for each patient population. Parameters were varied by $\pm 25 \%$. The variables altered, including their lower and upper values, are shown in the supplementary material (Table S7). Costs where assumptions had been made, or where data had been sourced externally, were selected as variables for sensitivity analysis.

The ten variables with the greatest impact on the overall cost per event for each population considered in the model are presented in the supplementary material (Figs. S2-S5). The model was found to be insensitive to all inputs except those which have a large proportional impact on the results, e.g., the cost of diabetes-related hospital stays per episode.

\section{DISCUSSION}

The results indicate that ketosis events are a substantial cost to the NHS, whether treated at home or in NHS facilities. Resource use and associated costs for ketosis events treated at home are considerably lower than for those treated in NHS facilities, primarily because NHS care is the main driver of cost, but also because these patients/carers used fewer resources to resolve the ketosis. This suggests that patients/carers treating ketosis events at home are treating milder cases of ketosis with a shorter time to recovery. 
Table 5 Direct costs associated with a single ketosis event

\begin{tabular}{|c|c|c|c|c|c|c|}
\hline & \multicolumn{2}{|c|}{$\begin{array}{l}\text { Direct costs associated } \\
\text { with ketosis events } \\
\text { treated at home only }(\mathfrak{E})\end{array}$} & \multicolumn{2}{|c|}{$\begin{array}{l}\text { Direct costs associated } \\
\text { with ketosis events } \\
\text { treated at home and in } \\
\text { NHS facilities }(\boldsymbol{E})\end{array}$} & \multicolumn{2}{|c|}{$\begin{array}{l}\text { Weighted average of all } \\
\text { direct costs associated with } \\
\text { ketosis events }(\mathcal{E})\end{array}$} \\
\hline & $\begin{array}{l}\text { Adults } \\
(70 \%)\end{array}$ & $\begin{array}{l}\text { Children } \\
(66 \%)\end{array}$ & $\begin{array}{l}\text { Adults } \\
(30 \%)\end{array}$ & $\begin{array}{l}\text { Children } \\
\text { (33\%) }\end{array}$ & $\begin{array}{l}\text { Adults } \\
(100 \%)\end{array}$ & $\begin{array}{l}\text { Children } \\
(100 \%)\end{array}$ \\
\hline Ketone monitoring costs & 7.59 & 11.98 & 15.35 & 34.59 & 9.92 & 19.52 \\
\hline Glucose monitoring costs & 3.18 & 4.47 & 7.92 & 9.89 & 4.60 & 6.28 \\
\hline $\begin{array}{l}\text { Insulin (home administration) } \\
\text { costs }\end{array}$ & 0.20 & 0.10 & 0.27 & 0.31 & 1.00 & 0.80 \\
\hline Insulin pump set change costs & 4.43 & 4.68 & 3.05 & 7.79 & 4.02 & 5.72 \\
\hline Phone call costs & 3.92 & 14.15 & 11.88 & 19.39 & 6.31 & 15.90 \\
\hline Appointment costs & 4.56 & 2.61 & 16.18 & 17.92 & 8.05 & 7.71 \\
\hline $\begin{array}{l}\text { NHS facility, staff, and } \\
\text { treatment costs }\end{array}$ & 0.00 & 0.00 & 162.92 & 263.03 & 48.88 & 87.68 \\
\hline Total & 23.87 & 38.00 & 217.57 & 352.92 & 81.98 & 142.97 \\
\hline
\end{tabular}

NHS National Health Service

The findings showed that pediatric ketosis events were associated with greater resource use and therefore greater cost than in adults. Pediatric carers accessed or used resources such as phone services more than adult patients and sought HCP assistance more frequently. In general, however, pediatric patients did not progress to DKA following treatment as frequently as adult patients $(12 \%$ of pediatric patients versus $26 \%$ of adult patients), which suggests this increased resource use may be associated with improved patient outcomes.

Compared with the direct cost of the average severe and non-severe episode of hypoglycemia [1], a well-understood acute complication in T1DM, ketosis events were associated with greater resource use and consequently were more expensive to treat and manage [1]. While it was not a focus of this study and no associated costs were calculated, results also indicate an associated impact on children's education and on presenteeism for carers. It should be noted that resource use was much greater than perceived by HCPs in the qualitative interview investigation, further suggesting that resource use during ketosis events is underappreciated.

Some limitations of this study should be acknowledged. Our survey population was small, particularly in comparison with a previous study into the resource use associated with hypoglycemia with similar methodology [19], and while no discrimination was made when inviting eligible adults and carers of children with T1DM to participate in our research, responding individuals were not wholly representative of the full population. However, we were able to recruit patients from a diverse range of backgrounds, including both young adults with T1DM who are thought to be at high risk for adverse outcomes due to changing life circumstances, competing life priorities, and decreased parental involvement [20] and older adults with T1DM who are at increased risk of complications, cognitive decline, and physical disability [21]. All participants reported data from an experience within the last 12 months, and over $50 \%$ of participants reported data from an experience within the last 3 months, which is considered to be an adequate period for the 


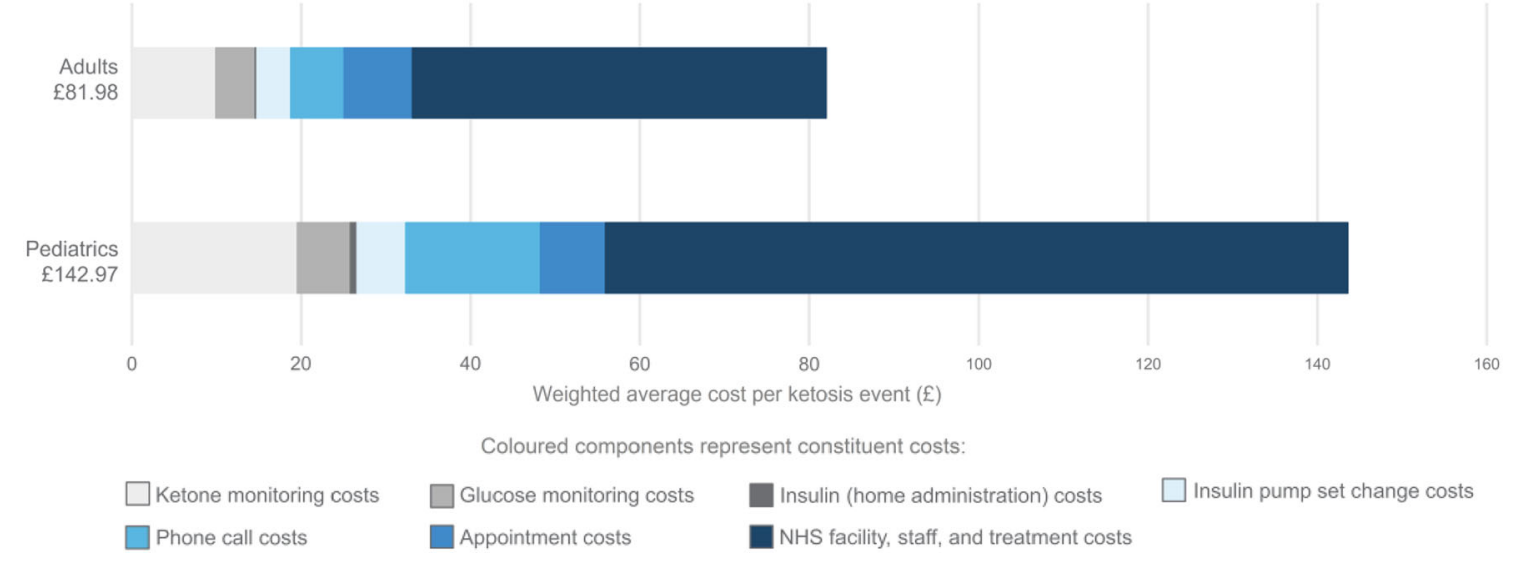

Fig. 3 Weighted averages of direct costs associated with ketosis events

accurate recall of experiences [22]. However, it is possible that recall bias may have caused slight errors in reports of resource use, and we were unable to corroborate reported values with healthcare records. Several assumptions were made in calculations, and as a result of the lack of information on the patient experience of ketosis events in the literature, we have been unable to compare our findings to previous research and cannot assess how accurate our findings might be. Incidence of ketosis was estimated on the basis of data from the ADJUNCT trial [16]. However, the ADJUNCT trial defined a ketosis event as plasma ketone levels greater than $1.5 \mathrm{mmol} / \mathrm{L}$, i.e., considerably higher than $0.6 \mathrm{mmol} / \mathrm{L}$ at which patient guidelines recommend treatment initiation. Additionally, clinical trial populations are generally closely monitored and compliant; the incidence of ketosis and associated population-level cost are likely to be significantly greater in the general population. However, we are confident that our methodology has allowed us to provide a good estimate of the resource use and associated costs of a ketosis event in individuals with T1DM in the UK.

\section{Implications for Ketosis Management}

Utilization of ketone strips, glucose strips, and insulin by patients and carers indicates that most patients are correctly following the sick-day rules $[11,12]$. However, while NICE recommends that pediatric patients should use blood ketone strips rather than urine ketone strips [10], our findings suggest that a large proportion of carers do not currently have access to them.

Where possible, efforts should be made to prevent ketosis events in patients with T1DM. Insulin management is key, and all patients should receive education about avoiding insulin omission, especially in times of illness. A flat profile of action of the basal component of the insulin treatment might be beneficial to maintain appropriate levels of insulin and prevent ketosis. Indeed, a study has found that rates of hyperglycemia with ketosis in a pediatric population are significantly lower amongst those using insulin degludec versus those using insulin detemir [23].

This study identified that the biggest cost associated with ketosis events is caused by the treatment of events in NHS facilities. While severe ketosis events in which patients are likely to progress to DKA should indeed be treated by HCPs, many ketosis events may be treated in the home, especially if they are recognized early. A UK study has shown that DAFNE significantly reduces the incidence of DKA (from 0.07 to 0.03 episodes/patient/year) [24], but our findings identified that only $42 \%$ of eligible survey respondents had completed a DAFNE course, and only $27 \%$ of patients/carers felt they "completely" understood how to identify and manage raised ketone levels. It is likely that many instances of ketosis treated in NHS 
facilities could instead be treated at home. Our findings suggest that there may be an unmet need for education in the recognition and home management of ketosis events.

Furthermore, patients and carers should be made aware of phone service assistance available to them which aim to improve confidence in administering home treatment. It has been demonstrated previously that access to telephone helplines reduces the rates of hospital admission for diabetic complications [25]. While NICE states that both pediatric carers and adults should have access to a 24 -h phone service $[9,10]$, our results indicate that not all patients either have access to such a service or are aware that one is available to them.

\section{CONCLUSIONS}

Ketosis events are an underexplored source of resource use in T1DM and an underappreciated source of economic burden for the NHS, especially with regards to pediatric patients. Resource use, and therefore incurred cost, extends beyond hospital care and into the home. For example, in addition to the use of ketone strips, glucose strips, pump set changes, and treatment with insulin, patients also use various phone services and lose time at work. Resource use extends beyond the ketosis event itself as many patients continue close ketone and glucose monitoring in the days and weeks following the event, and they often receive follow-up phone calls or face-to-face appointments with HCPs. Finally, there are other societal consequences beyond those to the NHS including work productivity loss and missed schooling.

Direct costs associated with ketosis events are higher than for hypoglycemia, ranging from $£ 23.87$ for adult patients treated in the home to $£ 352.92$ for pediatric patients treated with HCP assistance. The overall weighted cost of ketosis events may be estimated as $£ 81.98$ for adults and $£ 142.97$ for children. The inclusion of indirect costs from work productivity loss increases these costs even further. Improved management and effective treatment of ketosis events in T1DM will improve patient outcomes, reduce healthcare resource use, and thereby reduce NHS costs.

\section{ACKNOWLEDGEMENTS}

Funding for this research and article processing charges were provided by Novo Nordisk A/S. All authors had full access to all data in this study and take complete responsibility for the integrity of the data and accuracy of the data analysis.

All named authors meet the International Committee of Medical Journal Editors criteria for authorship for this manuscript, take responsibility for the integrity of the work as a whole, and have given final approval for the version to be published.

We thank Pati Diamantopoulou for assistance with the research design and Jens Gundgaard, Magnus Ekelund, and our anonymous peer-reviewers for comments that greatly improved the manuscript. Editorial assistance in the preparation of this manuscript was provided by Alan Weids and Rebecca Sullivan of DRG. Support for this assistance was funded by Novo Nordisk A/S.

Disclosures. Jonas Håkan-Bloch is an employee of Novo Nordisk A/S. Nandu Thalange has received fees for speaking and consulting from Novo Nordisk A/S. Natalie Valerie Jane Aldhouse is an employee of DRG Abacus, a health outcomes agency that consults with various pharmaceutical companies. Helen Kitchen is an employee of DRG Abacus, a health outcomes agency that consults with various pharmaceutical companies. Daniel Howard is an employee of DRG Abacus, a health outcomes agency that consults with various pharmaceutical companies.

Compliance with Ethics Guidelines. The need for a full ethics review was discussed with the North-West Research Ethics Committee (ethics committee reference number 60/32/07) and was deemed unnecessary. All procedures followed were in accordance with the ethical standards of the responsible committee on human experimentation (institutional and 
national) and with the Helsinki Declaration of 1964, as revised in 2013. Informed consent was obtained from all patients for being included in the study. The study was also conducted in line with National Institute of Health Research Good Clinical Practice [13] and British Healthcare Business Intelligence Association ethical standards [14]. All data was anonymized and held confidentially.

Data Availability. The interview guides and surveys used in the current study are available in the supplementary material. Datasets are available from the corresponding author on reasonable request.

Open Access. This article is distributed under the terms of the Creative Commons Attribution-NonCommercial 4.0 International License (http://creativecommons.org/licenses/ by-nc/4.0/), which permits any noncommercial use, distribution, and reproduction in any medium, provided you give appropriate credit to the original author(s) and the source, provide a link to the Creative Commons license, and indicate if changes were made.

\section{REFERENCES}

1. Parekh W, Ashley D, Chubb B, Gillies H, Evans M. Approach to assessing the economic impact of insulin-related hypoglycaemia using the novel Local Impact of Hypoglycaemia Tool. Diabet Med. 2015;32(9):1156-66

2. Laffel L. Ketone bodies: a review of physiology, pathophysiology and application of monitoring to diabetes. Diabetes Metab Res Rev. 1999;15(6):412-26.

3. $\mathrm{Ng} \mathrm{S}$, Soni A, Agwu J, et al. Clinical guideline: management of type 1 diabetes mellitus during illness in children and young people under 18 years (Sick Day Rules). https://www.bsped.org.uk/ clinical/docs/Sick_day_guideline_Main.pdf (2016). Accessed 17 Oct 2016.

4. Wright J, Ruck K, Rabbitts R, et al. Diabetic ketoacidosis (DKA) in Birmingham, UK, 2000-2009: an evaluation of risk factors for recurrence and mortality. Br J Diabetes Vasc Dis. 2009;9(6):278-82.
5. Health and Social Information Centre. National diabetes inpatient audit 2015: National report. http://content.digital.nhs.uk/catalogue/PUB20206/ nati-diab-inp-audi-15-nat-rep.pdf (2016). Accessed 17 Oct 2016.

6. Health and Social Information Centre. National diabetes audit 2012-2013: Report 2: Complications and mortality. http://content.digital.nhs.uk/ catalogue/PUB16496/nati-diab-audi-12-13-rep2.pdf (2015). Accessed 17 Oct 2016.

7. Department of Health. NHS reference costs 2014 to 2015. https://www.gov.uk/government/uploads/ system/uploads/attachment_data/file/480791/201415_National_Schedules.xlsx (2015). Accessed 17 Oct 2016.

8. Kitabchi AE, Nematollahi LR. BMJ best practice: diabetic ketoacidosis. http://bestpractice.bmj.com/ best-practice/monograph/162/highlights/summary. html (2016). Accessed 17 Oct 2016.

9. NICE. Type 1 diabetes in adults: diagnosis and management (NG17). http://nice.org.uk/guidance/ ng17 (2015). Accessed 4 Nov 2016.

10. NICE. Diabetes (type 1 and type 2 ) in children and young people: diagnosis and management (NG18). http://nice.org.uk/guidance/ng18 (2015). Accessed 4 Nov 2016.

11. NICE. Clinical Knowledge Summaries. Diabetestype 1. Scenario: management-adults. 'Sick-day rules'. http://cks.nice.org.uk/diabetes-type1\#!scenarioclarification:2 (2016). Accessed 4 Nov 2016.

12. NICE. Clinical Knowledge Summaries. Diabetestype 1. Scenario: management-children and young people. 'Sick day rules.' http://cks.nice.org. uk/diabetes-type-1\#!scenarioclarification:27 (2016). Last Accessed 4 Nov 2016.

13. NIHR. Good Clinical Practice. http://www.nihr. ac.uk/our-faculty/clinical-research-staff/learningand-development/national-directory/good-clinicalpratice/. Accessed 4 Nov 2016.

14. BHBIA. Legal and ethical guidelines. https://www. bhbia.org.uk/guidelines/legalandethicalguidelines. aspx (2016). Accessed 4 Nov 2016.

15. Tukey J. Exploratory data analysis. Reading: Addison-Wesley; 1977.

16. Mathieu C, Zinman B, Hemmingsson JU, al. Efficacy and safety of liraglutide added to insulin treatment in type 1 diabetes: the ADJUNCT ONE treat-to-target randomized trial. Diabetes Care. 2016;39(10):1702-10. 
17. Diabetes UK. Facts and stats. https://www.diabetes. org.uk/About_us/What-we-say/Statistics/ (2015). Accessed 8 Nov 2016.

18. Office for National Statistics. United Kingdom population 2015 mid-year estimate. https://web.archive. org/web/20161119183858/https://www.ons.gov.uk/ peoplepopulationandcommunity/populationand migration/populationestimates (2016). Accessed 9 Nov 2016.

19. Brod M, Christensen T, Thomsen TL, Bushnell DM. The impact of non-severe hypoglycemic events on work productivity and diabetes management. Value Health. 2011;14(5):665-71.

20. Agarwal S, Garvey KC, Raymond JK, Schutta MH. Perspectives on care for young adults with type 1 diabetes transitioning from pediatric to adult health systems: a national survey of pediatric endocrinologists. Pediatr Diabetes. 2016;. doi:10. 1111/pedi.12436.

21. Dhaliwal R, Weinstock RS. Management of type 1 diabetes in older adults. Diabetes Spectr. 2014;27(1):9-20.
22. O'Cathain A, Knowles E, Nicholl J. Testing survey methodology to measure patients' experiences and views of the emergency and urgent care system: telephone versus postal survey. BMC Med Res Methodol. 2010;10:52.

23. Thalange $\mathrm{N}$, Deeb L, Iotova $\mathrm{V}$, et al. Insulin degludec in combination with bolus insulin aspart is safe and effective in children and adolescents with type 1 diabetes. Paediatr Diabetes. 2015;16(3):164-76.

24. Elliott J, Jacques R, Kruger J, et al. Substantial reductions in the number of diabetic ketoacidosis and severe hypoglycaemia episodes requiring emergency treatment lead to reduced costs after structured education in adults with type 1 diabetes. Diabet Med. 2014;31(7):847-53.

25. Hoffman WH, O'Neill P, Khoury C, Bernstein SS. Service and education for the insulin-dependent child. Diabetes Care. 1978;1(5):285-8. 